\title{
María Belén Tell \\ Tras la huella del testimonio. Estudio filosófico sobre los silenciosos alcances de la antropología hermenéutica de Paul Ricoeur
}

\author{
Servicio de Publicaciones Universidad Pontificia de Salamanca, \\ Salamanca, España \\ Fecha de publicación: 18/03/2015 (1ª edición), pp. 288, \\ ISBN: 978-84-16066-28-5
}

El libro "Tras la huella del testimonio. Estudio filosófico sobre los silenciosos alcances de la antropología hermenéutica de Paul Ricoeur" de la autora Maria Belén Tell, goza ya en sus primeras páginas de una recensión bastante profunda y sutil, de la mano del Prof. Dr. D. Francisco-Javier Herrero Hernández, quien prologa la obra con palabras y juicios que ya revelan el alcance de la misma, puesto que "el contento que provoca [el] libro es por haber tomado en serio la labor filosófica de ir a las cosas mismas, en este caso, el esfuerzo de ir al problema radical del hombre y quizá, o muy probablemente, hasta del mismo Dios como objeto principal de la investigación [...]" (p. 20). Consideramos que en estas pocas palabras quedaría concentrado, tal vez, el propósito perseguido en el presente texto.

El libro constituye el fruto de un hondo y concienzudo trabajo de investigación filosófica, el cual gira en torno en sentido amplio, podría decirse, a la controversia entre filosofía y fe, al problema entre razón, fe y antropología-religiosa; y en sentido estricto, hace hincapié sobre "la ambigua relación, pero al tiempo fecunda, entre la filosofía y la fe en el pensamiento de Paul Ricoeur [...]". En este sentido, son varios aspectos los interesantes y que llaman la atención, dado que 
tal "vínculo" no se despliega de cualquier manera, sino que se pronuncia "en el centro mismo del desarrollo antropológico... en el propio corazón de la antropología y hermenéutica del qui-soi" (p. 26), o sea, del quién/sí mismo.

Antes de explayarnos de lleno en la metodología y estructura de la obra, cabe señalar que son tres los rasgos más relevantes de la misma, a saber: en primer lugar, el problema entre fe y filosofía en el autor P. Ricoeur, y que tal problemática se desenvuelve en el "entre" de las dos dimensiones de la antropología hermenéutica ricoeuriana, la filosófica y la bíblica respectivamente. En segunda instancia, se reconoce que el propio dinamismo de la antropología del filósofo francés -y como ámbito privilegiado de encuentro entre razón, reflexión, religiosidad y fe-, va dirigiendo la lectura hacia la exigencia de re-formular en una renovada expresión dicho recorrido ricoeuriano, llegando de este modo al esbozo final y decisivo de una inédita expresión, tanto en su sentido como en sus alcances. Y por último, tal hermenéutica antropológica y redefinida en su significación, se postularía sagazmente como un puente posible que edifique las bases de una "antropología de la paz". Sólo por estos tres elementos medulares y que se van concatenando de modo argumentado y armónico en el transcurso de los distintos capítulos, consideramos que estamos ante un texto que vale la pena leer y confrontar. Dicho con otras palabras, esta obra es un intento por devolverle a la reflexión filosófica su densidad existencial y compromiso en primera persona.

El sendero que conduce o sigue el rastro de la "Huella del testimonio", oscila permanentemente en un «entre» de dos expresiones centrales, y a las cuales Ricoeur echa mano en su antropología hermenéutica, ellas son el acusativo en francés de "Heme aquí" ("Me voici!") y el imperativo "Tú Ámame" ("Toi, Aimemoi!"), y en cuya relación silenciosa se fraguan los posibles alcances de dicho estudio filosófico, yendo claramente -y varias veces confirmado por su autora- más allá de los objetivos y propósitos del filósofo contemporáneo, pero asegurando que este más allá no pierde ni un ápice de seriedad ni validez en su despliegue. Podría decirse, con otras palabras, que este tácito juego acontece en el 'entre' de la filosofía y de la supra-filosofía, puesto que la exégesis bíblica le dona generosamente a la actividad filosófica, y sin perder su autonomía ni autenticidad, una serie de vocablos y expresiones que dan curso a un nuevo tipo de "pensar", un pensar gestado en el cruce, en la amistad entre filosofía y fe bíblica respectivamente. En este sentido, se propone una "novedosa antropología" en el recorrido hermenéutico de Ricoeur, así como una curiosa, por calificarla de alguna manera, vinculación entre fe y filosofía. 
A continuación con la estructura del texto, se nota que la obra está diagramada en seis capítulos, de una densidad y envergadura que cabe mencionar. El primer capítulo presenta la correspondiente ubicación del tema/problema en su marco teórico y estado de la cuestión filosófica actual, en el cual se destaca por cierto un riguroso y completo itinerario bibliográfico, dando cuenta de un tipo de abordaje inédito, audaz y creativo al respecto. En este capítulo el tópico a investigar queda ampliamente justificado, así como presentado el dilema entre los registros fe y filosofía.

Una vez ubicada y fundamentada la cuestión a investigar, los capítulos segundo y tercero, de gran minuciosidad y análisis también, muestran el desarrollo del soi-même, a través de la filosofía de la voluntad y de la hermenéutica filosófica del quien propiamente tal, así como de su estructura fundamental originaria en tensión-mediación, comprendiendo a la obra completa del autor en armónica unidad y coherencia. En tales capítulos se abordan prolijamente distintas obras del filósofo poniendo en evidencia, sobre todo en el tercer acápite, la tesis de que la palabra humana no constituye ni la última ni la primera palabra, puesto que el soi-même/me voici en su "puro" despliegue filosófico, fenomenológico/hermenéutico, se ubica en el entre o en medio de otra Palabra. Temática que se profundiza en el capítulo cuarto, dado que aquí el eje central reside en la articulación de la antropología hermenéutica del autor francés, en su doble dimensión filosófica y bíblica, a través de un análisis pormenorizado del "órgano-en-relación" que define a la conciencia. Este capítulo es medular, y consideramos que constituiría el punto de inflexión en el recorrido hermenéutico, ya que se muestra de forma aguda y original la continuidad de la problemática, pudiéndose corroborar así que el proyecto antropológico de Ricoeur conforma un todo consistente e integrado internamente.

El capítulo quinto, presenta la llave maestra o clave de comprensión, y según las propias palabras de la autora, porque permiten visualizar la hondura del problema, deslizado desde el vínculo entre filosofía y fe hacia la dialéctica entre "amor y justicia" respectivamente, dado que la dinámica entre la hermenéutica bíblica y la filosófica se ve consolidada por esta dialéctica entre una lógica racional propiamente dicha, y otra sobreabundante y amorosa, en la cual cada una no se des-configura en absoluto de su propia identidad. Tales dialécticas proceden en el 'entre' de la "economía del don", asunto que conduce al lector al paulatino encuentro de los personajes-modelos de testimonio, que erigirán el centro de la concreción de dicha dialéctica entre amor y justicia, y entre fe y filosofía. Lo significativo que se muestra de modo ingenioso y refinado, 
radica en la comprensión y el sentido que adquiere el "testimonio", dado que solo gracias a esta categoría es posible contemplar y "resolver", si es que cabe esta expresión, la/s controversia/s o ambigüedad/es sobre la/s que se indaga en el transcurso de los apartados.

Ulteriormente, el sexto y último capítulo intenta denominar o re-definir dicho itinerario hermenéutico, arriesgando con harta perspicacia y cautela aquella "novedad" sigilosa perseguida en la antropología filosófica ricoeuriana. Dicha antropología hermenéutica oscilante en el 'entre' del "me voici" y el "toi aime moi", del amor y la justicia, entre la fe y la filosofía, quedará redefinida como una «antropología hermenéutica-existencial fundamental relacional», con toda la hondura y alcance que dicha re-formulación reviste; dado que cada uno de sus términos fue rigurosa y fehacientemente argumentado en este capítulo, así como confrontado con otras posibles nomenclaturas pero que no daban suficiente cuenta en sentido estricto de lo aquí evaluado y valorado.

El libro culmina con una serie de conclusiones y alcances, preanunciadas en la introducción y puestas allí concisamente en seis afirmaciones finales, que de alguna manera recuperan y resumen el despliegue meticulosamente trazado, a través de cada capítulo, y gracias a un serio y maduro ejercicio de examen crítico y meditación filosófica.

No quisiéramos, sin embargo, dejar de mencionar el breve excursus sobre "la labor del filósofo hoy", y que antecede a las conclusiones finales, porque en aquel el testimonio se postula como un "nuevo pensamiento". En otros términos, ya no sería un "pensar sobre...", sino que la existencia del propio "testimonio" constituiría una nueva lógica, un "renovado pensar", un inédito modo de comprender y reflexionar filosóficamente pero no separándolo del genuino compromiso con la existencia. Puesto que el testimonio, en tanto "prueba viviente de la convicción", es aquel quien-sí mismo buscado y encontrado en cuanto realidad gnoseo-epistemológica, antropológica, religiosa y existencial, en el vértice relacional entre lo racional y lo supra-racional, entre dos preguntas y dos respuestas que no se contraponen, entre el anhelo ético de la justicia y la opción y decisión meta-ética y definitiva por el amor, y en donde el "sentido" abordado fenomenológico-hermenéuticamente se desplazó luego hacia un plus excedente, que sólo en la realidad del amor halla su ulterior y radical significado y fundamento.

Más allá de la calidad investigativa de esta obra y de sus alcances técnicos, el libro es un testimonio profesional en sí mismo, el de una filósofa cristiana que se atreve a mantener el rigor y autonomía de su disciplina, pero sin cerrarse a que las inspiraciones, las mociones y los horizontes puedan venir de otras fuentes.

\section{Universidad Santo Tomás, Facultad de Teología}


En este caso, de la Palabra originaria, que tanto para el judaísmo como para el cristianismo ha dado y sigue dando tantos frutos y tantas luces.

Dr. Patricio Merino Beas

Instituto de Teología UCSC, Concepción, Chile.

CEBITEPAL, Bogotá, Colombia.

Facultad de Teología Universidad Santo Tomás de Aquino,

Bogotá, Colombia. 